\title{
Patricia Touboul, Le statut des femmes: nature et condition sociale dans le traité «De l'éducation des filles» de Fénelon
}

\section{Lagier}

\section{(2) OpenEdition}

Journals

Édition électronique

URL : http://journals.openedition.org/studifrancesi/36047

DOI : 10.4000/studifrancesi.36047

ISSN : 2421-5856

Éditeur

Rosenberg \& Sellier

Édition imprimée

Date de publication : 1 juillet 2005

Pagination : 156

ISSN : 0039-2944

\section{Référence électronique}

M. Lagier, «Patricia Touboul, Le statut des femmes: nature et condition sociale dans le traité «De l'éducation des filles» de Fénelon », Studi Francesi [En ligne], 145 (XLIX | I) | 2005, mis en ligne le 30 novembre 2015, consulté le 20 avril 2021. URL : http://journals.openedition.org/studifrancesi/36047 ; DOI : https://doi.org/10.4000/studifrancesi.36047

Ce document a été généré automatiquement le 20 avril 2021.

\section{cc) $(9)$}

Studi Francesi è distribuita con Licenza Creative Commons Attribuzione - Non commerciale - Non opere derivate 4.0 Internazionale. 


\title{
Patricia Touboul, Le statut des femmes: nature et condition sociale dans le traité «De l'éducation des filles» de Fénelon
}

\author{
M. Lagier
}

\section{RÉFÉRENCE}

PATRICIA TOUBOUL, Le statut des femmes: nature et condition sociale dans le traité «De

l'éducation des filles» de Fénelon, «Revue d'histoire littéraire de la France », avril-juin 2004, pp. 325-342.

1 Bien que dans son traité sur L'Éducation des filles Fénelon ait protesté contre le caractère négligé de celle-ci, on a tendance à faire de son œuvre un condensé des opinions misogynes et traditionnalistes de son siècle. P. Touboul conteste cette lecture trop partiale en proposant une approche plus nuancée des positions anthropologiques, religieuses, métaphysiques et politiques de cet auteur. Pour Fénelon, en effet, il n'y a pas au départ de sexe faible ni de sexe fort, mais un être indifférencié, l'enfant, dont la malléabilité organique est facteur de liberté et de flexibilité. Ce premier âge s'achève avec la seconde naissance de l'enfant, qui coïncide avec l'acquisition du langage et de la raison. S'opère alors une différenciation des sexes qui est déjà le résultat d'un conditionnement. Ainsi on empêche les filles de quitter véritablement le monde de l'enfance et on les habitue à se conformer à la représentation que l'on se fait des femmes. Or on peut attendre autre chose de celles-ci et c'est ici qu'intervient l'instruction, dont le rôle pour Fénelon est fondamental dans le développement des aptitudes potentielles. Certes il conseille de faire plus appel à l'imagination qu'à la raison lorsqu'il s'agit d'éduquer les filles, mais la raison est bien souvent synonyme d'autosuffisance, et si, pour Fénelon, la tâche des femmes est de gouverner la maison, cela inclut aussi la gestion des terres et donc la maitrise de connaissances économiques 
et juridiques. Elles doivent par ailleurs connaître tout ce qui relève de l'éducation des enfants, détenant ainsi, y compris au plan théologique, l'avenir du genre humain. Au contre exemple de la femme dangereuse et séductrice, produit d'une éducation mal comprise, s'oppose alors le véritable modèle vers lequel l'être féminin est en droit de tendre: la femme forte des Proverbes. 